\title{
Determination of structure ordering parameters in subsurface layers of condensed state materials by AMD-methods
}

\author{
Alexander Kustov ${ }^{1}$, Igor Derkachev ${ }^{1}$, Irina Miguel ${ }^{2, *}$ and Mikhail Kulakov ${ }^{3}$ \\ ${ }^{1}$ Voronezh State Pedagogical University, Faculty of physics and mathematics \\ ${ }^{2}$ Military Training Research Center of the Air Force of the Air Force Academy named after Professor \\ N. E. Zhukovsky and Yu. A. Gagarin (Voronezh), Russia \\ ${ }^{3}$ BONN Elektronik GmbH, Ohmstr. 11, DE-83607 Holzkirchen, Deutschland
}

\begin{abstract}
The results of studies of solid-state materials using AMDmethods are presented. It is shown that, regardless of the type of structure of the studied materials and their nature, acoustic waves provide subsurface images. The proposed methods allow measuring the velocity of surface acoustic waves and their level of attenuation. These characteristics and acoustic images make it possible to evaluate the parameters of ordering the structure of subsurface layers of materials.
\end{abstract}

\section{Introduction}

The study of materials in a condensed state is still an urgent material science task. In the vast majority of cases, the near-surface layers of materials are of interest, since they are largely responsible for the physical and mechanical properties of materials or products $[1,2]$. The structure or structure of these subsurface, internal regions of materials can be effectively studied using modern research methods called AMD-methods [3-4]. Algorithms for their application were considered earlier [5-7]. They are based on obtaining images of the structure of materials using acoustic waves (AW) at various depths from the surface and analyzing these images. In addition, there are a number of AMD-methods that allow you to calculate the absolute values of a number of acoustic characteristics of the studied samples or determine their relative changes under external influences. It is based on the analysis of interference curves $(\mathrm{V}(\mathrm{Z})$-curves) obtained using a scanning acoustic microscope (SAM), which are characteristic of each material $[8,9]$. It is these AMD-methods that are proposed to be used to determine the parameters of structure ordering in subsurface layers of materials. The relevance of this problem is not in doubt, since numerous experiments have shown that the structure of a material determines the level of its properties, and first of all, the structure of subsurface layers.

\footnotetext{
*Corresponding author : vuaik@mail.ru
} 


\section{Experimental data}

AMD-methods provide images of the structure at various depths from the surface, by moving the acoustic lens along the axis. This does not require complex operations to etch the surface of the samples. For fig. 1 shows an example of acoustic visualization of the steel structure.

The optical image does not show any parameters of the sample structure, while the acoustic image obtained without additional surface treatment also shows grains, and their size and shape are reliably determined. Studies of the structure and determination of its parameters are particularly effective when the acoustic visualization method is supplemented with the $\mathrm{V}(\mathrm{Z})$-curve method $[10,11]$. These interference curves have two characteristic regions - the main peak region and the small oscillation region [12]. The first is related to the level of AW-attenuation in the subsurface layers of samples, and the second is related to the velocity of surface acoustic waves (surfactants) in them. By experimentally measuring the height of the main maximum of the $\mathrm{V}(\mathrm{Z})$-curve, or the distance between the side maxima $\Delta \mathrm{Z}_{\mathrm{N}}$, the values of the attenuation coefficient $(\Delta \mathrm{V} / \mathrm{V} \%)$ and the velocity $\left(\mathrm{U}_{\mathrm{R}}\right)$ of surface acoustic waves are calculated from expressions 1 and 2 [13].

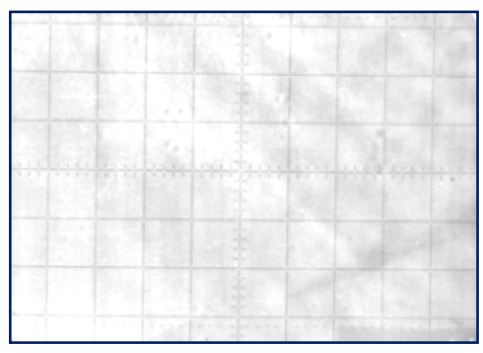

a)

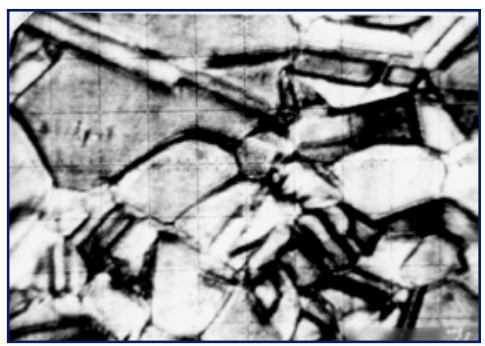

b)

Fig.1. Optical $\sim 200 \mathrm{x}(a)$ and acoustic $(b)$ images of subsurface layers of VNS-2M steel; scale: 28 micrometers / div., $\mathrm{Z}=-12$ micrometers, $\mathrm{H}_{2} \mathrm{O}, f=407 \mathrm{MHz}$ ).

$$
\Delta \mathrm{Z}_{N}=\frac{v_{l}}{2 \cdot f} \cdot\left[1-\sqrt{1-\left(\frac{v_{l}}{v_{R}}\right)^{2}}\right]^{-1} \text { (1) } v_{R}=v_{l} \cdot\left[1-\left(1-\frac{v_{l}}{2 \cdot f \cdot \Delta Z_{N}}\right)^{2}\right]^{-\frac{1}{2}}
$$

In the above expressions $f$ is the frequency of scanning acoustic microscope (SAM); $\theta_{R}$ - angle Rayleigh, $\lambda_{R}$ is the length of the surface acoustic wave, $\lambda_{l}$ is the length of the longitudinal waves in an immersion fluid; $v_{l}$ - the velocity of longitudinal waves in an immersion fluid, $N$ is the number of maxima in $\mathrm{V}(\mathrm{Z})$-curve.

The properties of subsurface layers are determined by the characteristics of structural elements, such as grain size and shape, and depend on the degree of deformation and the presence and parameters of defect systems. Changing these characteristics leads to a change in the shape of the $\mathrm{V}(\mathrm{Z})$-curves, which can be used to determine the degree of impact. For fig. 2 presents one of the confirmations of this thesis, demonstrating the influence of the degree of deformation on the appearance of characteristic regions of $\mathrm{V}(\mathrm{Z})$-curves. 


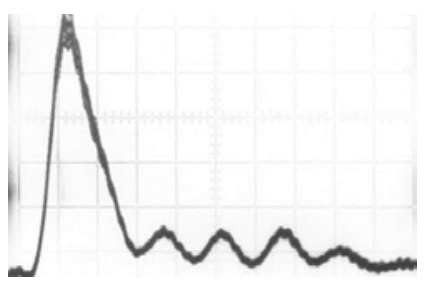

a)

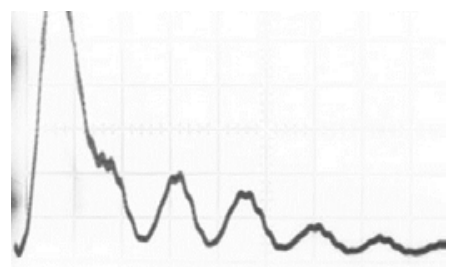

b)

Fig. 2. Change in the $V(Z)$-curve due to changes in the elastic-mechanical parameters of the studied steel with degrees of deformation of $7 \%$ and $38 \%$ (respectively, $\mathrm{UR}_{\mathrm{R} 1}=3.03 \cdot 10^{3} \mathrm{~m} / \mathrm{s}$ and $\mathrm{U}_{\mathrm{R} 2}=$ $3.14 \cdot 10^{3} \mathrm{~m} / \mathrm{s}$.

By measuring the grain size of steels from acoustic images or from the transformation of $v_{R}$ values, the values of their known characteristics were calculated and compared with certain other, standard methods. It turned out that the values of these characteristics coincided within the margin of error $[13,14]$.

For example, for steels of St.70, 15H2NMFA, 08H18N10T, 06H14N8MD2T and others, Hall - Peach dependences (3) were obtained by AMD-methods:

$$
\sigma_{0,2}=\sigma_{0}+k d_{g}^{-1 / 2},
$$

where $\sigma_{0}$ and $k$ are constants for this material. In all the considered cases, the analysis of the $\sigma_{0,2}-d_{g}$ - dependence allowed calculating the constants $\sigma_{0}$ and $k$ based on the test results for two grain sizes. Using these constants allowed us to calculate the corresponding values $\sigma_{0,2}$.

In addition, for 40HNFA steels, and 35HNFA $\sigma_{0,2}$-values were calculated for states characterized by different grain sizes. For 35HNFA steel, it was determined using AMDvisualization. It was equal to 33 microns for $\left(\sigma_{0,2}\right)_{1}=820 \mathrm{MPa}$ and 13 microns for $\left(\sigma_{0,2}\right)_{2}=908 \mathrm{MPa}$. For steel 40HNVA similar calculations gave 9 microns for $\left(\sigma_{0,2}\right)_{2}=1048 \mathrm{MPa}$ and 27 microns for $\left(\sigma_{0,2}\right)_{1}=937 \mathrm{MPa}$. Accordingly, for 35HNFA steel, the constants $\sigma_{0}$ and $k$ were $673 \mathrm{MPa}$ and $0,8410^{6}\left(\mathrm{MPa} / \mathrm{mcm}^{-1 / 2}\right)$, and for 40HNVA steel, $788 \mathrm{MPa}$ and $0,79 \cdot 10^{6}\left(\mathrm{MPa} / \mathrm{mcm}^{-1 / 2}\right)$. These data are in good agreement with data obtained by other methods $[14,15]$.

For fig.3 provides information about changes in the level of acoustic wave attenuation $(\Delta \mathrm{V} / \mathrm{V} \%)$ depending on the distance to the sample surface. The stronger the impact (shot blasting operations), the greater the change in the attenuation coefficient of surface acoustic waves. AMD-methods allow us to calculate the thickness of a layer with properties changed during steel deformation up to 3-5 microns.

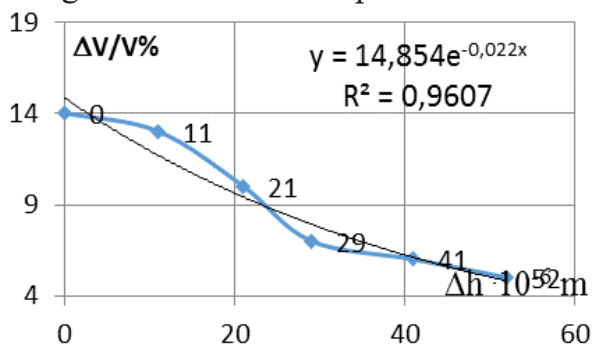

a)

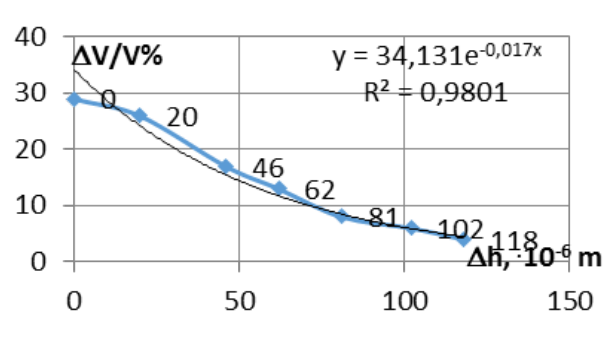

б)

Fig. 3. Dependence of the layer thickness with changed properties $\Delta \mathrm{h}$ in $15 \mathrm{H} 2 \mathrm{NMFA}$ steel, determined by the degree of AW attenuation $(\Delta \mathrm{V} / \mathrm{V} \%)(a$-sand $0.05 \mathrm{~mm}$, b-fraction $0.4 \mathrm{~mm})$ 


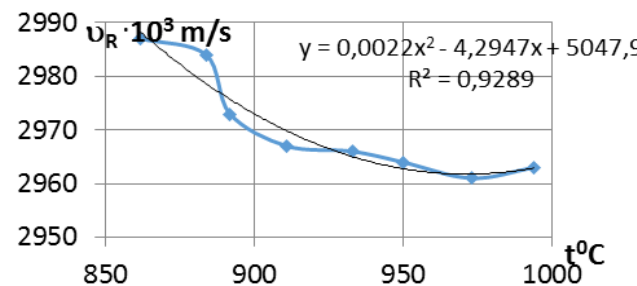

a)

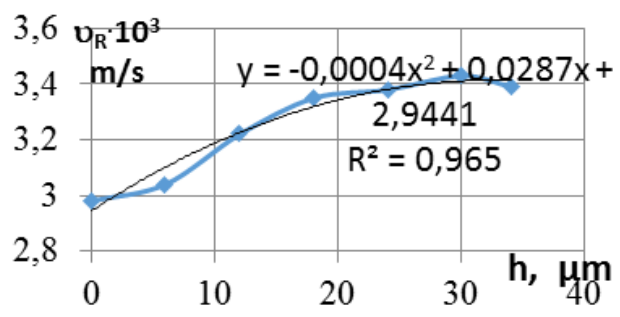

b)

Fig. 4. Dependences of the surfactant velocity on the quenching temperature of steel 09G2S $(a)$ and the change in the velocity in steel $08 \mathrm{H} 18 \mathrm{~N} 10 \mathrm{~T}$ depending on the depth of the nitrided layer $(b)$

AMD-methods are also sensitive to the parameters of thermal and chemical heat treatment. In support of this thesis, figures 4 and 5 show the results of using SAM to analyze the state of materials after steel quenching, nitriding, and cementation. Changing the process parameters leads to a transformation of the acoustic characteristics of samples, which are used to calculate the thickness of the impact layer, local values of the yield strength, and so on.

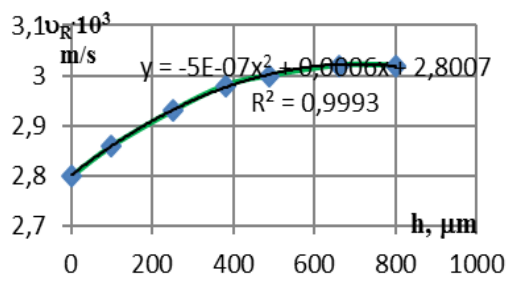

a)

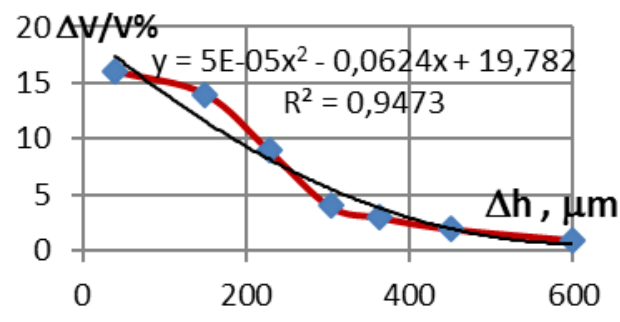

b)

Fig. 5. $a-25 \mathrm{H} 2 \mathrm{GNTA}$ - dependence of the surfactant velocity on the distance to the sample surface after the cementation process; b-18H2N4VA - dependence of the SAW absorption level on the thickness of the nitrided layer (nitriding process temperature $560^{\circ} \mathrm{C}, 40 \mathrm{~h}$, layer $\sim 370$ micrometers)

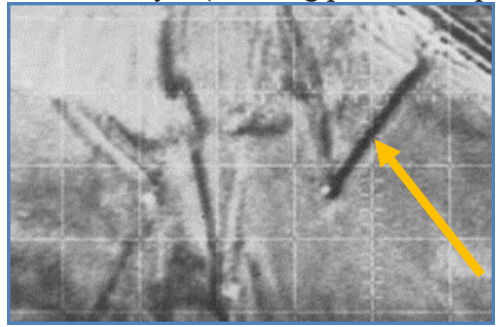

a)

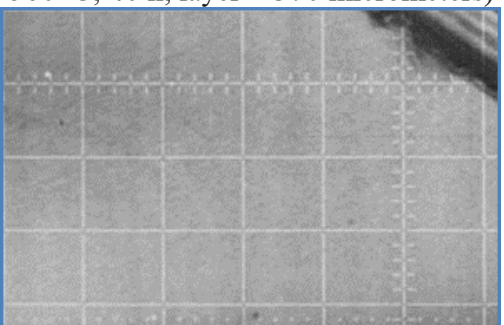

b)

Fig. 6. Acoustic image of $(a)$ a section of a steel sample with a fatigue crack (scale 20 micrometers / div., frequency $=406 \mathrm{MHz}, \mathrm{Z}=-24$ micrometers, and $(b)$ an optical image of this section of the surface $\left(350^{\mathrm{x}}\right)$. 


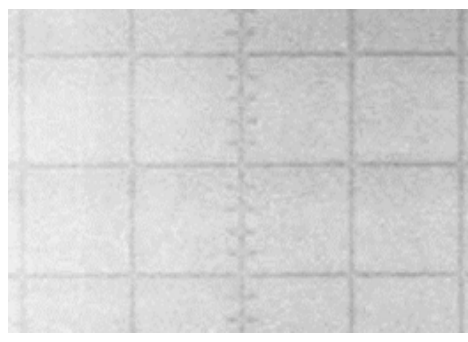

a)

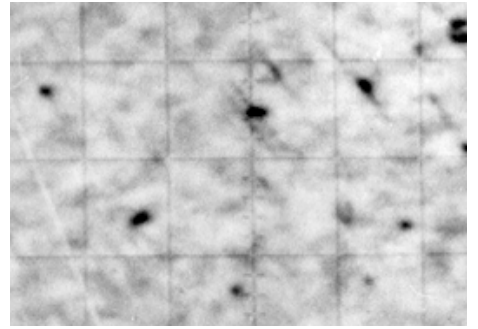

b)

Fig. 7. Optical (a) $210^{\mathrm{x}}$ and acoustic image with $Z=-7$ micrometers $(b)$ of subsurface layers of steel with pitting corrosion $(08 \mathrm{H} 21 \mathrm{~N} 6 \mathrm{M} 2 \mathrm{~T}$, scale 35 micrometers / div., $f=402 \mathrm{MHz}$.

In addition to the deformation process, defects, their size, shape, and distribution in space play an important role in influencing the properties of the material. As a result of deformation, primarily of the subsurface layers of objects, or for other reasons (for example, during pitting corrosion), unstable local States may occur in the material, which turn into dangerous defects of the type. nano- and microcracks. These conditions are effectively detected by AMD- methods (see Fig. 6,7). Getting a set of spatial distribution of microdefects, you can build boundary surfaces that allow you to reliably detect critical States of materials. One of these surfaces is shown in figure 8 .

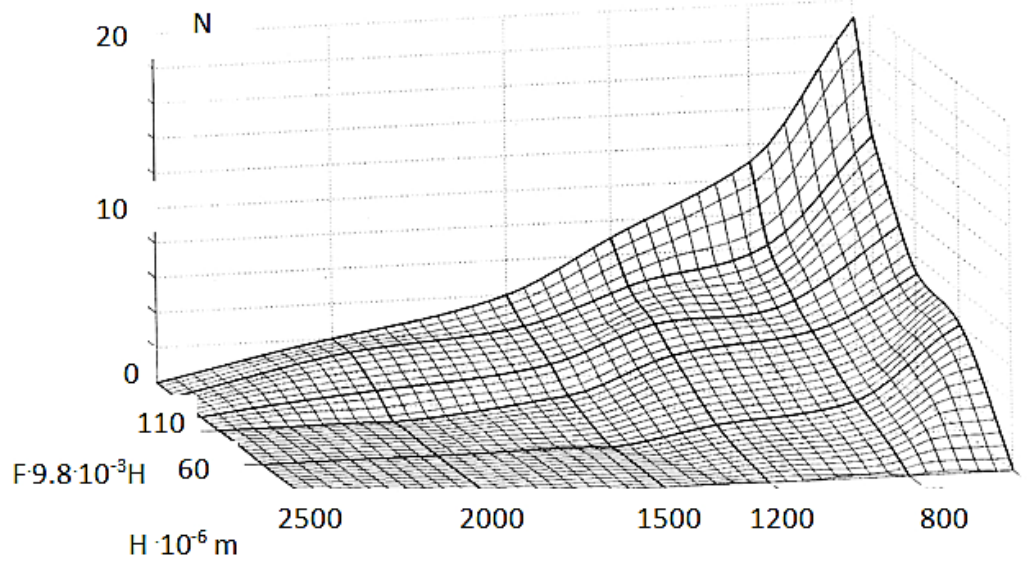

Fig. 8. The effect of the residual thickness $(\mathrm{H})$, the pressure of the cutting tool $(\mathrm{F})$ on the number of defects occurring in the sample volume $(\mathrm{N})$, detected by SAM in the K-108-glass.

Identification of microdefects is effectively implemented using the $\mathrm{V}(\mathrm{Z})$-curves method, according to the degree of their transformation (Fig. 9). Obtaining an acoustic image of an area with a modified shape of the $\mathrm{V}(\mathrm{Z})$-curve leads to visualization of a defect that is not detected in optical images (Fig. 10).

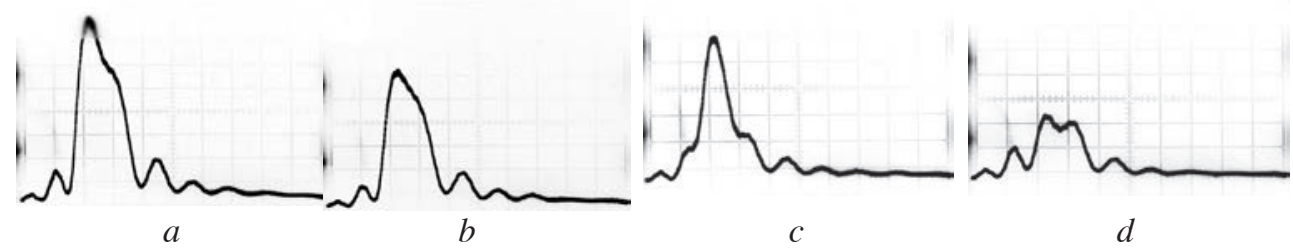

Fig. 9. Transformation of the $\mathrm{V}(\mathrm{Z})$-curve in the microdefect region in a $\mathrm{Ge}<111>$ single crystal (UR $=2.87 \cdot 10^{3} \mathrm{~m} / \mathrm{s}, \Delta \mathrm{Z}_{\mathrm{N}}=13.25$ micrometers, $(\Delta \mathrm{V} / \mathrm{V} \%) \max =68 \%$, vertical scale 1 div. $=0.25 \mathrm{~V}$, horizontal scale -1 div. $=11$ micrometers). 
However, the main task of this work was to analyze the degree of ordering of solid objects. It is this characteristic that determines the change in the properties of samples. The value of $v_{R}$, as well as the height of the main maximum of $\mathrm{V}(\mathrm{Z})$-curves, are informative characteristics of the object that allow calculating its physical and mechanical parameters (for example, elastic modules E and G, porosity, density, level of defects, etc.) [5,6]. Figure 11 shows examples of visualization of steel structures after various types of deformation. The estimation of differences in elastic modules along the selected directions in steels is shown in Fig. 12 and indicates a high sensitivity of AMD-methods. Figures 13 and 14 show the differences in the physical characteristics of samples along the selected directions that were detected using AMD-methods. Note that both the values of SAW velocities and the level of their attenuation are sensitive to the texture.
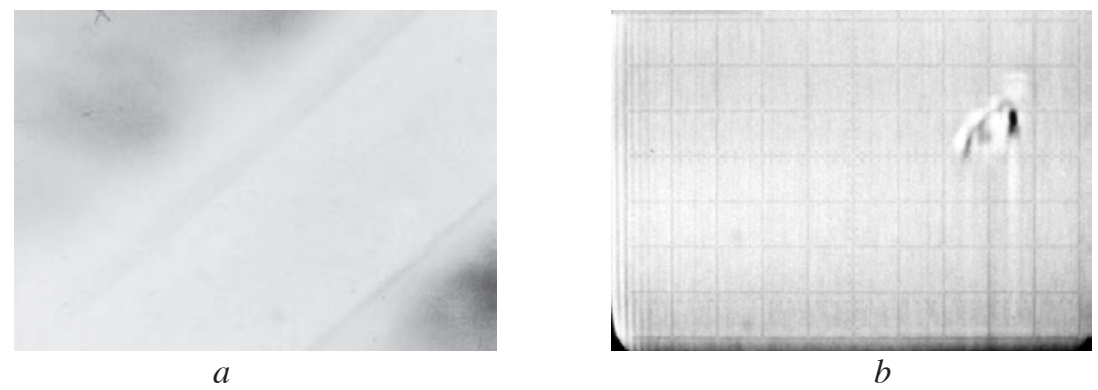

Fig. 10. Optical (per lumen) ( $a$ ) and acoustic $(b)$ images of subsurface layers in the region of elastic inhomogeneity in the glass K-108; (a) magnification $\sim 100^{\mathrm{x}}$; b) $\mathrm{H}_{2} \mathrm{O}$, residual thickness 690 microns, $f$ $=404 \mathrm{MHz}, \mathrm{Z}=-18$ microns, scale 18 microns/div.).

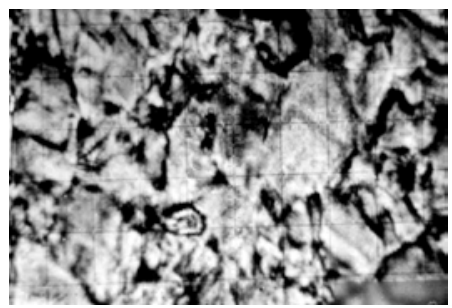

a)

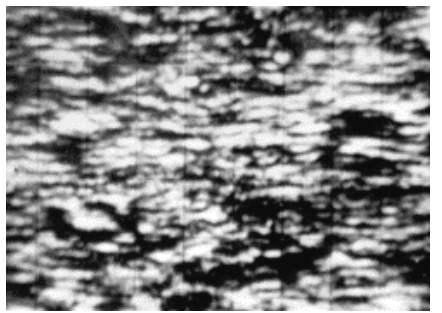

b)

Fig. 11. $a$-AMD-images obtained due to the acoustic contrast gradient of individual grains $(50 \%$ degree of deformation, the image plane is perpendicular to the rolling direction; scale 40 microns/div., $\mathrm{H}_{2} \mathrm{O}, \mathrm{Z}=-14$ microns); $\mathrm{b}$ - microstructure of steel subjected to patenting (scale $28 \mu \mathrm{m} / \operatorname{div} ., f=407$ $\left.\mathrm{MHz}, \mathrm{Z}=-12 \mu \mathrm{m} ; \mathrm{H}_{2} \mathrm{O}\right)$.

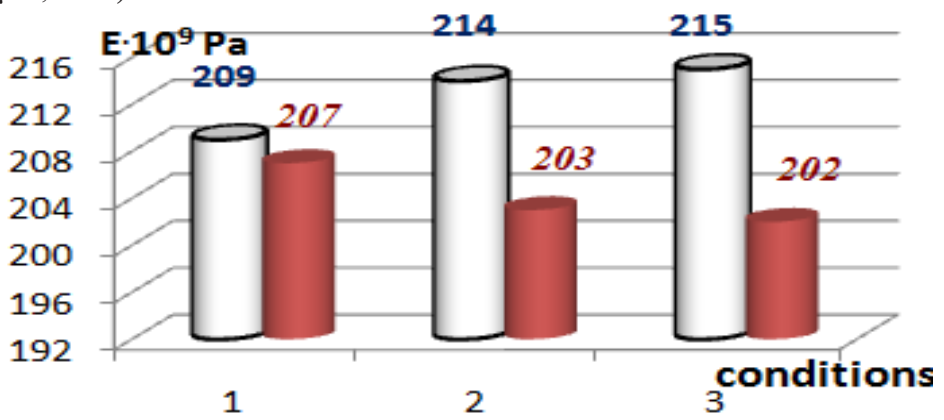

Fig. 12. Anisotropy of elastic modules of steel (40HNMA) after its deformation and patenting (1under delivery conditions; 2 -after $30 \%$ deformation; 3 - after patenting operation); left column - for structures parallel to the direction of deformation, right column - for structures perpendicular to the direction of deformation. 


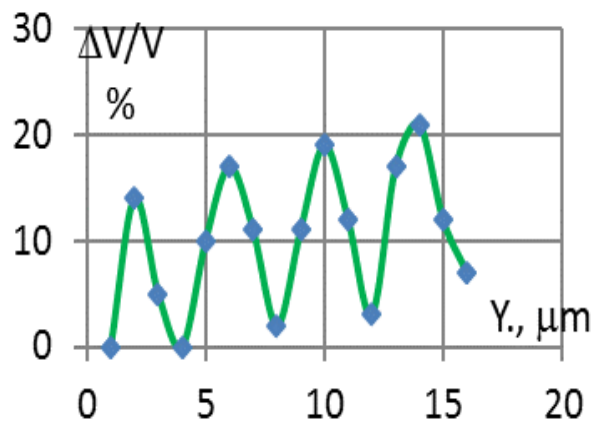

a)

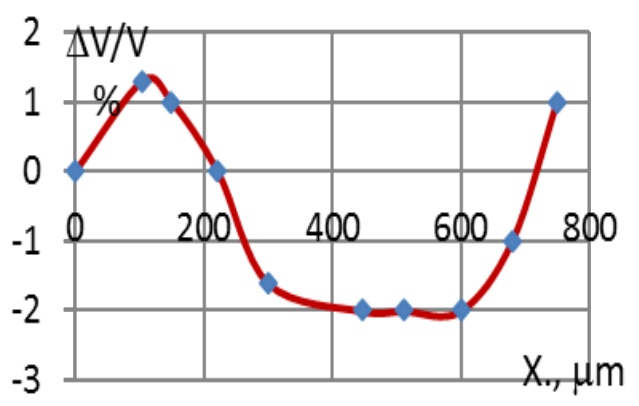

b)

Fig. 13. Change in the $A B$ absorption level in 27HGSNL steel sample after torsional deformation (the surface is perpendicular to the strain axis- $a$, the surface is parallel to the strain axis- $b$ ).

The study of ceramics and composites deserves special consideration, since these objects are formed using powder technologies or by creating solid particle structures in a liquid matrix. By changing the matrix viscosity, varying the solidification time and the spatial distribution of particles, you can change the set parameters in a wide range. As an influence parameter for piezoceramics, it is necessary to use the polarization process. The results of the first experiments with these materials obtained using AMD-methods are shown in Fig. 15,16. They confirm the effectiveness of using AW for acoustic visualization of the structure of such materials, assessing their porosity, and determining the degree of ordering. Ultimately, the data obtained allow us to correct the production process of such materials to obtain extremely high property parameters.

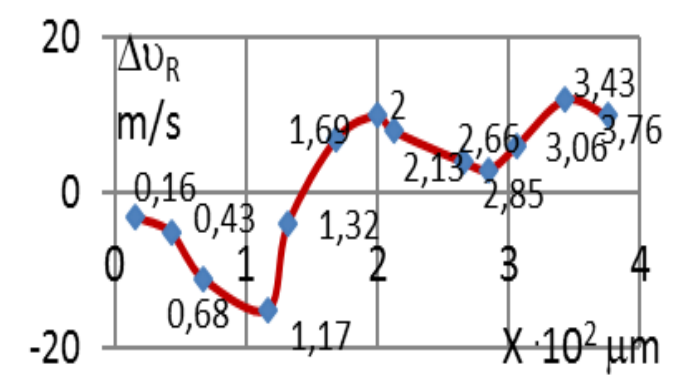

a)

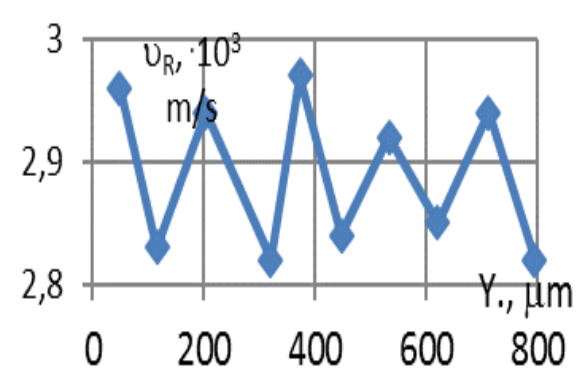

b)

Fig. 14. Velocity dispersion of surface acoustic waves (SAW) $(a)$ along the $\mathrm{Z}$ axis in 25H2GNTA steel with a grain size $\left(\mathrm{d}_{\mathrm{z}}\right)^{-1 / 2} \sim 8$ and $(b)$ - change in the velocity of SAWin an aluminum alloy (AMG-5) subjected to torsional deformation in a plane perpendicular to the rolling plane. 


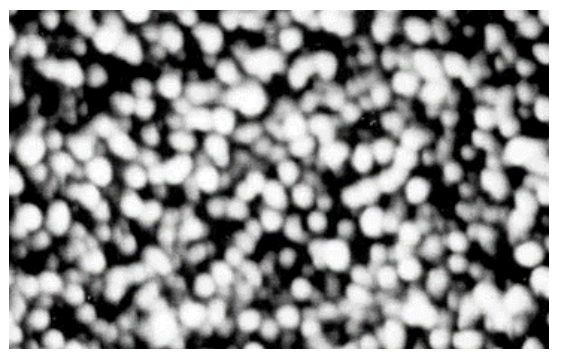

a)

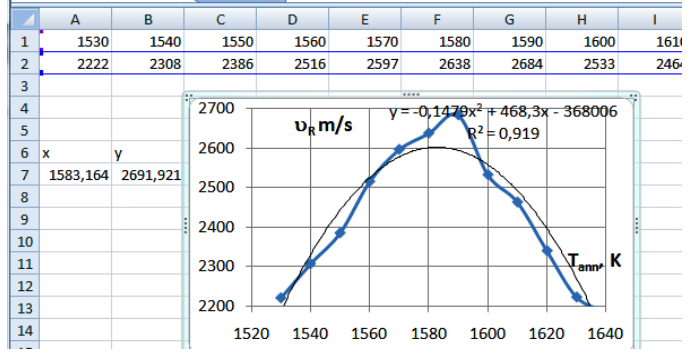

b)

Fig. 15. Acoustic image $(a)$ of the structure of the PZT-19 layer at a depth of $\sim 32$ microns (frequency $404 \mathrm{MHz}$, horizontal size 250 microns), (b) - the dependence of $\mathrm{U}_{\mathrm{R}}$ on the $\mathrm{T}_{\mathrm{ann}}$ for PZT-35, for which the optimization algorithm is applied

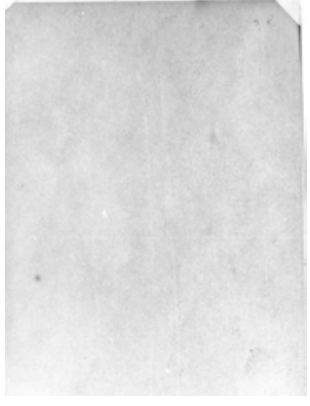

a)

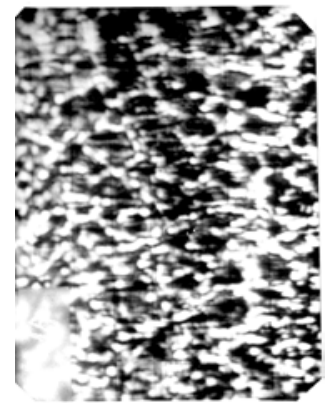

b)

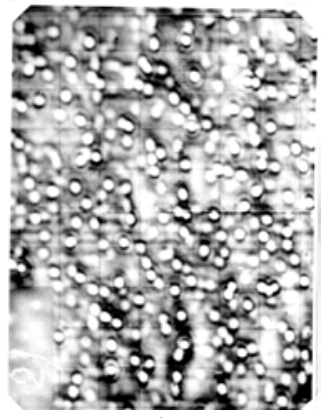

c)

Fig. 16. Optical (a) and acoustic-microscopic (b) and (c) images of the composite NV-1 and PZT-19 (404 MHz, scale 40 microns/div. with varying degrees of filler saturation, vertical fill; $Z_{\mathrm{b}-\mathrm{g}}=-40$ microns).

Thus, experiments have shown that AMD-methods are effective in determining the parameters of structure ordering in near-surface layers of materials. At the same time, it does not matter the nature of the material or its structure - all of them are transparent to acoustic waves and allow you to use both the acoustic visualization method and the $V(Z)$ curve method. We believe that research in this area should be continued.

\section{References}

1. Irvin, D. Zh., Fundamentals of the theory of crack growth and destruction / D. Zh. Irvin, P. Paris // Destruction. T. Z. / ed. g. Libovits. - M.: Mir, 1976. - P. 17-66.

2. Atalar A., J. Appl. Phys., 1979 - v.50 - №12 - p.8237-8239.

3. Weaver J.M.R., Ilett C., Somekh M.G., Briggs G.A.D., Metallography . 1985 . V.17 . p. 3-34.

4. Weglein R.D., Wilson R.F., J. Appl. Phys., 1984. v.55. №9. p.3261-3275.

5. Kustov A. I., Miguel I. A., Fundamental problems of modern materials science., v. 11, no. 4/2., 2014. - pp. $592-598$.

6. Zelenev V. M., Miguel I. A., Kustov A. I., Fundamental problems of modern material science, 2019. №1 (16)., pp. 22-29.

7. Zelenev V.M., Migel I.A., Kustov A.I., Materials today: Proceedings., Volume 11., Issue P1., 2019., p.p.218-227

8. Maev R., Weinheim, Germany: Wiley-VCH, 2013. - 400 p.

9. Titov S. A., Mayev R. G., Bogachenkov A. N., Russian technological journal, 2016, 
Vol. 4, No. 2 (11), Pp. 25-30.

10. Kustov A.I., Miguel I.A. Bulletin of the Perm National Research Polytechnic University. Mechanical engineering, materials science. V.18. No 4., (2016) 134-146.

11. Zelenev V. M., Kustov A. I., Migel I. A., Materials today: Proceedings., Volume 19., Issue P1., 2019., p.p.2503-2506.

12. Kustov A. I., Migel I. A., Materials today: Proceedings., Volume 19., Issue P1., 2019., p.p.2507-2511.

13. Skorokhod V.V. Physical and mechanical properties of porous materials // Kiev., Nauk. dum.., 1977, 120 p.

14. Microwave Acoustics Handbook // Ed. Slobodnik, E.D. Conway, NY.: Office of aerospace Research United State Air Force. 1970. Vol.1. 228 p.

15. I. A. Viktorov. Sound superficial waves in solid bodies. M.: Science, 1981. 287 pages. 